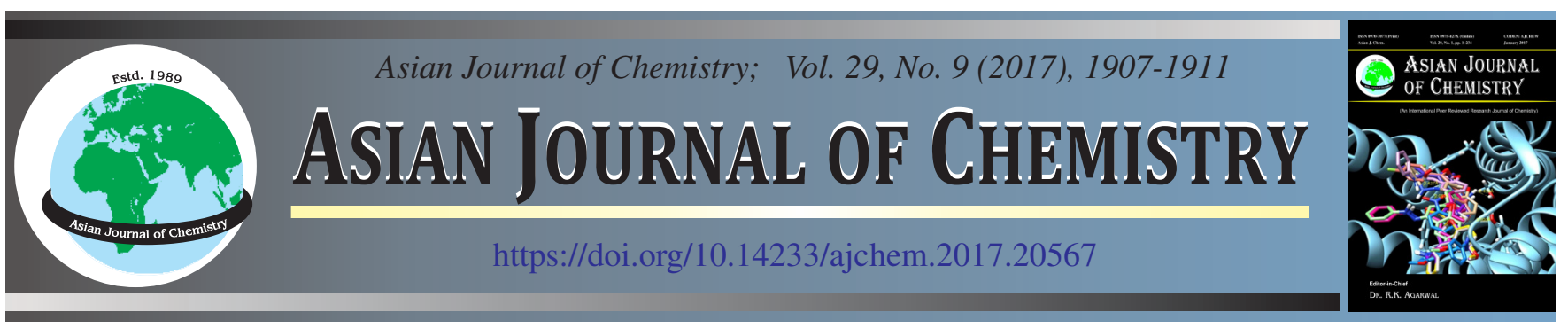

\title{
Effect of Concentration of Glycine Surfactant on Photocatalytic Properties of Zinc Oxide Nanoparticles for Photocatalytic Degradation of Methylene Blue
}

\author{
Roaya A. Almasoud ${ }^{1}$, Elham S. Aazam ${ }^{1}$ and Reda M. Mohamed ${ }^{1,2, *}$
}

${ }^{1}$ Chemistry Department, Faculty of Science, King Abdulaziz University, Jeddah 21589, P.O. Box 80203, Saudi Arabia

${ }^{2}$ Nanostructured Material Division Advanced Materials Department, Central Metallurgical R\&D Institute, Helwan, 11421 Cairo, Egypt

*Corresponding author: E-mail: redama123@yahoo.com; eaazam@yahoo.com

Hydrothermal method in presence of different concentration of glycine as surfactant was used to prepare zinc oxide nanoparticles. Different techniques were used to describe the prepared nanocomposites. This reveals that the concentration of glycine acting significant role in zinc oxide band gap. The zinc oxide nanoparticles photocatalytic performances were studied by measuring degradation of methylene blue under UV light. Photocatalytic parameters such as the concentration of glycine, photocatalyst dose of zinc oxide which prepared by $6 \mathrm{mmol}$ of glycine $(\mathrm{ZnO}-6 \mathrm{G})$ were studied.

Keywords: ZnO, Glycine, Degradation of methylene blue, UV light.

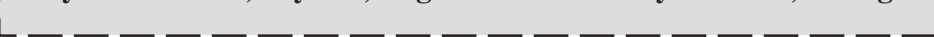

\section{INTRODUCTION}

With the rapid development of industry, a number of pollutant species are evolved as a result of different processes until make the final product from factories. The pollutant species are a wide range of materials that are harmful for soil, air, water, human body and all lives in our environment. Thus, the need for controlling and managing this environmental pollution is a must since it represented a human society major problem. Most of the pollutants are organic materials existing in wastewater from factories containing dyes and other toxins. By the discovery of photocatalysis [1], a tremendous work was offered to use semiconductor photocatalysts to destruct organic materials produced in wastewater [2-5]. The use of metal oxide semiconductors like $\mathrm{TiO}_{2}$ or $\mathrm{ZnO}$ photocatalyst for degradation of organic pollutants were severely studied in last decades [6,7]. Simply, the photocatalytic mechanism started with the generation of electron-hole pair that produced by excitation of the valence band electron of semiconductor via electromagnetic radiation photon with specific energy. Then, a redox reaction through the migration of this electron-hole pair initiated with oxygen and water. The formation of a reactive oxidation species ( $\mathrm{O}$ and $\mathrm{OH}$ radicals) is a later step that can oxidize the organic materials to small molecules such as $\mathrm{H}_{2} \mathrm{O}$ and $\mathrm{CO}_{2}[8,9]$. This process represents an energy efficient, green and simple concept for the real applications in wastewater treatment $[9,10]$. Among metal oxide semiconductors, zinc oxide is a important wide band gap compound with great band gap of $3.37 \mathrm{eV}$ besides its high electron mobility $[11,12]$. It can be formed in various structures with excellent electrical and optical properties. Moreover, zinc oxide can be produced using several methods with high yield at low price [13-16]. It has no pollution effect or high toxicity to the environment. Yet, the quick recombination of the photogenerated electron-hole pairs as well as the great band gap affects the photocatalytic performance that disturbs the practical applications. A number of efforts were done through the doping of $\mathrm{ZnO}$ with either metal or non-metal to get higher efficiency and reduce the so-called photo-etching to reduce both recombination rate and band gap [17-23]. Another problem facing the $\mathrm{ZnO}$ photocatalysts is the powdery nature, which is difficult for the separation or recycling purposes [24]. Titanium dioxide is widely used photocatalyst as it possesses properties that include chemical stability, non-toxicity, possible reuse, possible incorporation in other materials and favourable physical properties. However its wide band gap $\left(\mathrm{E}_{\mathrm{g}}=3.2 \mathrm{eV}\right)$ makes it active when used in reactions that involve UV light which constitute about 3-5\% of the solar spectrum; for this, researchers always try to manipulate its structure to narrow the band gab which in turn makes the derived material active in the natural or artificial sunlight [25-30]. The use of visible radiation allows conducting reactions in environmental friendly fashion with no need to energy from other sources. Many researchers are interested in designing catalysts with band energy that fall within the visible frequency [31-39]. Other required properties in catalysts include nontoxicity, stability, possible reuse, ease of separation, favourable 
magnetic and electric properties along with other characteristics depending on the application required. Therefore, a novel preparation of $\mathrm{ZnO}$ nanoparticles is essential for enhancing the photocatalytic properties of our nanomaterial. The present work is aimed to synthesize via hydrothermal technique. In the operated process glycerin has been consumed for synthesizing of $\mathrm{ZnO}$ for the first time as a matrix. The new designed materials will be also applied for methylene blue dye photocatalytic degradation.

\section{EXPERIMENTAL}

Preparation of photocatalysts: $2 \mathrm{mmol}$ of Glycerin $(\mathrm{G})$ was dissolved under magnetic stirring in bidistilled water (20 $\mathrm{mL}$ ). Then, $5 \mathrm{~g}$ of zinc nitrate was added to glycerin solution drop-wise and stirred for $60 \mathrm{~min}$ to form mixture solution. A mixture solution was transferred to Teflon line autoclave and heated for $24 \mathrm{~h}$ at $140{ }^{\circ} \mathrm{C}$. The produced washed many times by bidistilled water and ethanol and were dried in an oven at $100{ }^{\circ} \mathrm{C}$. The produced materials were calcined at $500{ }^{\circ} \mathrm{C}$ for $2 \mathrm{~h}$. The produced sample was named as $\mathrm{ZnO}-2 \mathrm{G}$. The above method was repeated three times to prepare 4, 6 and $8 \mathrm{mmol}$ of glycerin and their samples were named as $\mathrm{ZnO}-4 \mathrm{G}, \mathrm{ZnO}$ $6 \mathrm{G}$ and $\mathrm{ZnO}-8 \mathrm{G}$, respectively.

Photocatalysts characterization: The morphological, chemical and physical properties of $\mathrm{ZnO}$ nanoparticles were investigated using different characterization techniques. The texture properties and surface area analysis were performed using $\mathrm{N}_{2}$-adsorption measurements with a Nova 2000 series Chromatech apparatus at $77 \mathrm{~K}$, after degassing the samples for $2 \mathrm{~h}$ at $373 \mathrm{~K}$. Powder X-ray diffraction (XRD) was used to study the crystallinity of the samples using Bruker axis D8 with $\mathrm{CuK}_{\alpha}$ radiation $(\lambda=1.540 \AA)$ at room temperature. UV-Vis-NIR spectrophotometer (V-570, Jasco, Japan was used to determine the UV-Vis diffuse reflectance spectra (UV-Vis-DRS) to estimate the band gap performance over the range $200-800 \mathrm{~nm}$. Shimadzu RF-5301 fluorescence spectrophotometer was used to determine the photoluminescence emission spectra.

Photocatalytic activity: The photocatalytic activity test was studied by study degradation of methylene blue under UV light irradiation. The degradation reactions were carried out in a Pyrex glass beaker. The photocatalytic activity experiment was performed by adding $0.1 \mathrm{~g}$ of photocatalyst into the beaker with $300 \mathrm{~mL}$ aqueous methylene blue solution (50 $\mathrm{ppm})$. This mixture was placed inside the photocatalytic reactor for $60 \mathrm{~min}$ and then $\mathrm{O}_{2}$ flow was bubbled through the reactor with constant flow rate to keep the mixture homogeneous. The reaction was initiated irradiation process when the UVlamp was switched on. The experiment was performed at room temperature and $\mathrm{pH}$ about 7 . The resulting mixture was taken after irradiation and the catalyst separated from solution by centrifugation process. After that, the content of methylene blue in the solution after irradiation was determined by monitor the absorbance of methylene blue solutions under constant experimental conditions using UV-visible spectrophotometer which was recorded on a Shimadzu UV-2450 with $1 \mathrm{~cm}$ (path length) quartz cuvette. The photodegradation efficiency of methylene blue was calculated by applying the following equation:

$$
\text { Photodegradation efficiency }(\%)=\frac{\mathrm{C}_{0}-\mathrm{C}}{\mathrm{C}_{0}} \times 100
$$

where $\mathrm{C}_{0}$ is the original content of methylene blue and $\mathrm{C}$ is the residual methylene blue in solution.

\section{RESULTS AND DISCUSSION}

Photocatalysts characterizations: The XRD patterns of $\mathrm{ZnO}$ nanoparticles prepared by different concentration of glycine are shown in Fig. 1. The results revealed that all samples consist from the signal phase of $\mathrm{ZnO}$. In addition, we noticed that the height of zinc oxide characteristic peaks were decreased by the increase concentration of glycine from 2 to $6 \mathrm{mmol}$. However, by increase concentration of glycine above $6 \mathrm{mmol}$ has no significant effect on crystallinity of the obtained zinc oxide nanoparticles. Therefore, the crystallinity of the prepared zinc oxide can be controlled by control concentration of glycine.

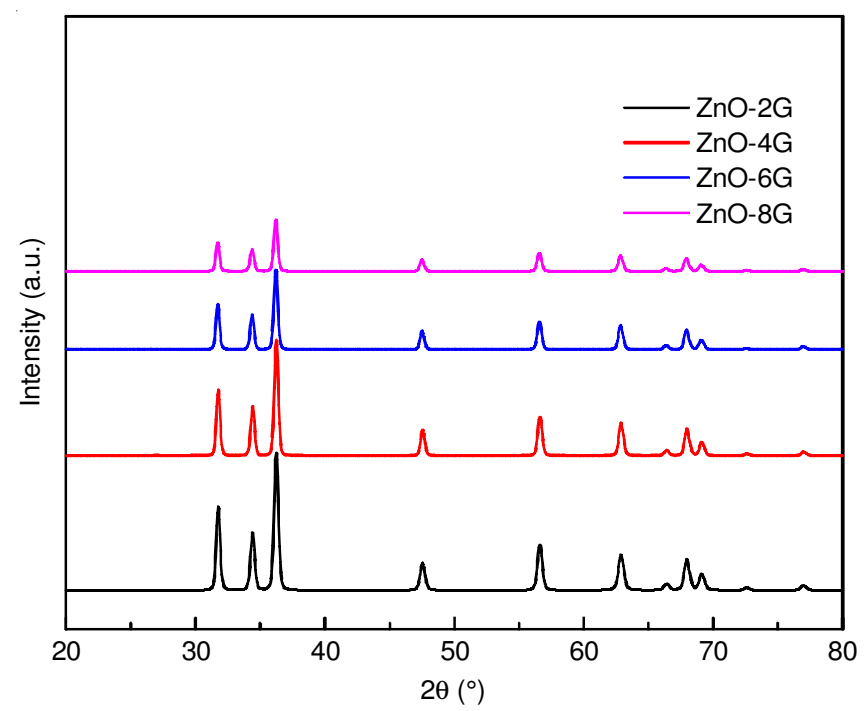

Fig. 1. XRD patterns of $\mathrm{ZnO}$ nanoparticles prepared by different concentration of glycine

The BET surface area of $\mathrm{ZnO}$ nanoparticles which prepared by different concentration of glycine is shown in Table-1. The results demonstrated that the values of surface area of $\mathrm{ZnO}-2 \mathrm{G}, \mathrm{ZnO}-4 \mathrm{G}, \mathrm{ZnO}-6 \mathrm{G}$ and $\mathrm{ZnO}-8 \mathrm{G}$ samples are 30, 40, 50 and $52 \mathrm{~m}^{2} / \mathrm{g}$, respectively. Therefore, addition of glycine increase the pores of the produced zinc oxide and so increase the specific surface area. Therefore, the BET surface area of prepared zinc oxide can be controlled by control concentration of glycine.

TABLE-1

BET SURFACE AREA OF ZnO NANOPARTICLES WHICH PREPARED BY DIFFERENT CONCENTRATION OF GLYCINE

\begin{tabular}{cc}
\hline Concentration of glycine $(\mathrm{mmol})$ & $\mathrm{S}_{\mathrm{BET}}\left(\mathrm{m}^{2} / \mathrm{g}\right)$ \\
\hline 2 & 30 \\
4 & 40 \\
6 & 50 \\
8 & 52 \\
\hline
\end{tabular}

Fig. 2 shows the UV-visible spectra of $\mathrm{ZnO}$ nanoparticles prepared by different concentration of glycine. The marks 


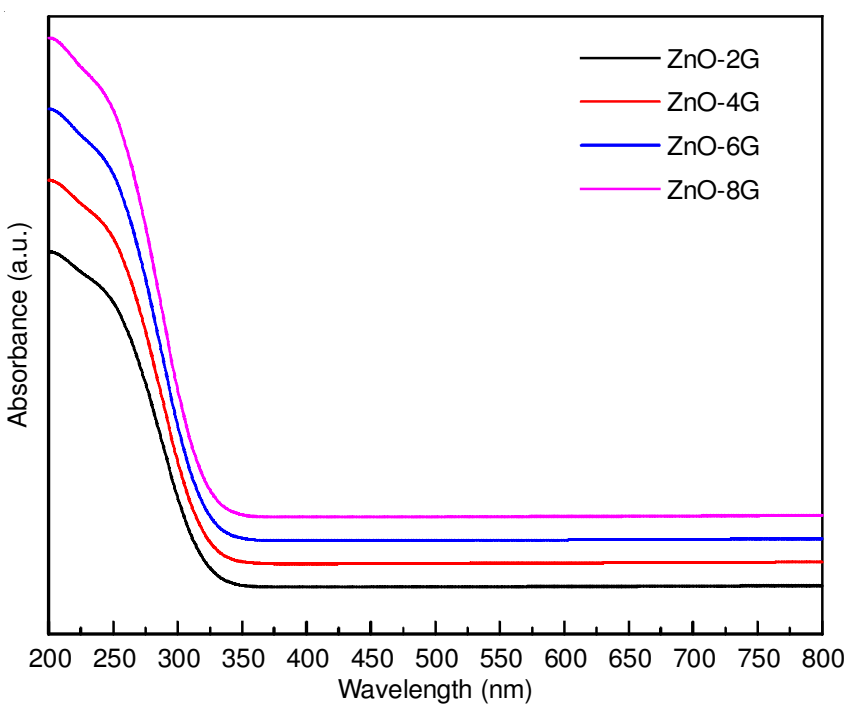

Fig. 2. UV-visible spectra of $\mathrm{ZnO}$ nanoparticles prepared by different concentration of glycine

demonstrated that the absorption edge of $\mathrm{ZnO}$ was shifted to a longer wavelength as glycine concentration was enlarged from 2 to $6 \mathrm{mmol}$. However, increase concentration of glycine above $6 \mathrm{mmol}$ has no significant effect on absorption edge of $\mathrm{ZnO}$ obtained. The band gap energy was calculated from the UVvisible spectra and tabulated in Table- 2 . The values obtained 3.4, 3.3, 3.2 and 3.18 eV, $\mathrm{ZnO}-2 \mathrm{G}, \mathrm{ZnO}-4 \mathrm{G}, \mathrm{ZnO}-6 \mathrm{G}$ and $\mathrm{ZnO}-8 \mathrm{G}$, respectively. Therefore, the band gap of prepared zinc oxide can be controlled by control concentration of glycine.

TABLE-2

BAND GAP OF ZnO NANOPARTICLES WHICH PREPARED BY DIFFERENT CONCENTRATION OF GLYCERINE

\begin{tabular}{cc}
\hline Concentration of glycerine $(\mathrm{mmol})$ & Band gap $(\mathrm{eV})$ \\
\hline 2 & 3.40 \\
4 & 3.30 \\
6 & 3.20 \\
8 & 3.18 \\
\hline
\end{tabular}

The photoluminescence spectra of $\mathrm{ZnO}$ nanoparticles prepared by different concentration of glycine is shown in Fig. 3. The position of photoluminescence peak of $\mathrm{ZnO}$ was shifted to a longer wavelength as glycine concentration was enlarged from 2 to $6 \mathrm{mmol}$. However, increase concentration of glycine above $6 \mathrm{mmol}$ has no significant effect on position of photoluminescence peak of $\mathrm{ZnO}$ obtained. The band gap energy was calculated from the photoluminescence spectra and the values obtained 3.5, 3.4, 3.2 and $3.19 \mathrm{eV}, \mathrm{ZnO}-2 \mathrm{G}$, $\mathrm{ZnO}-4 \mathrm{G}, \mathrm{ZnO}-6 \mathrm{G}$ and $\mathrm{ZnO}-8 \mathrm{G}$, respectively. Therefore, the band gap of prepared zinc oxide can be controlled by control concentration of glycine. Also, the results for band gap obtained from photoluminescence spectra are very close to UV results.

Photocatalytic activities: Effect of different concentration of glycine on photocatalytic activity of $\mathrm{ZnO}$ nanoparticles for degradation of methylene blue is shown in Fig. 4. The marks expose that increasing concentration of glycine from 2 to 6 mmol increases the photocatalytic activity of $\mathrm{ZnO}$ after 60 min from 20 to $100 \%$, respectively. In addition, we noticed that rising the concentration of glycine over $6 \mathrm{mmol}$ has no

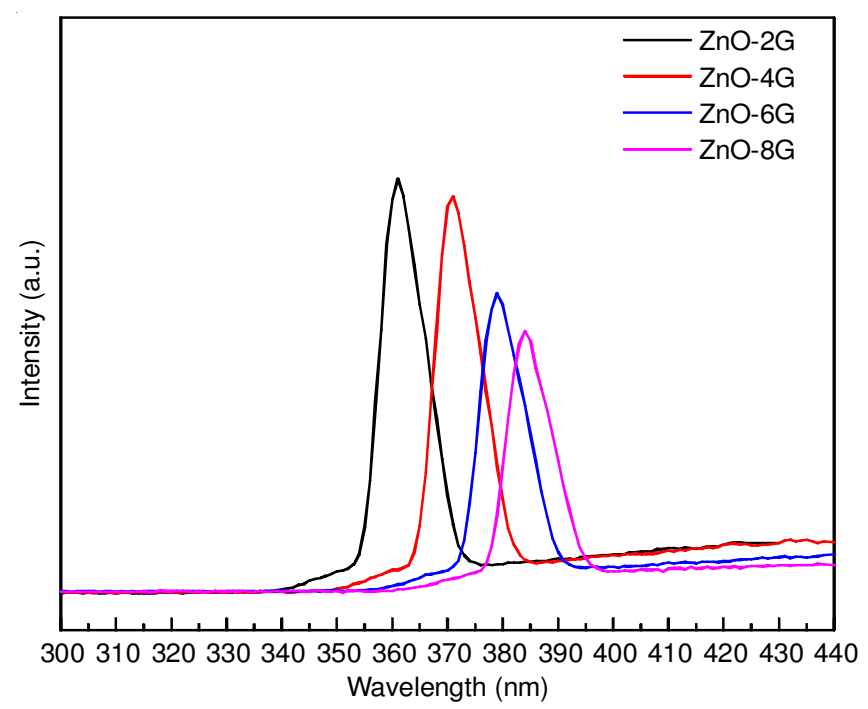

Fig. 3. Photoluminescence spectra of $\mathrm{ZnO}$ nanoparticles prepared by different concentration of glycine

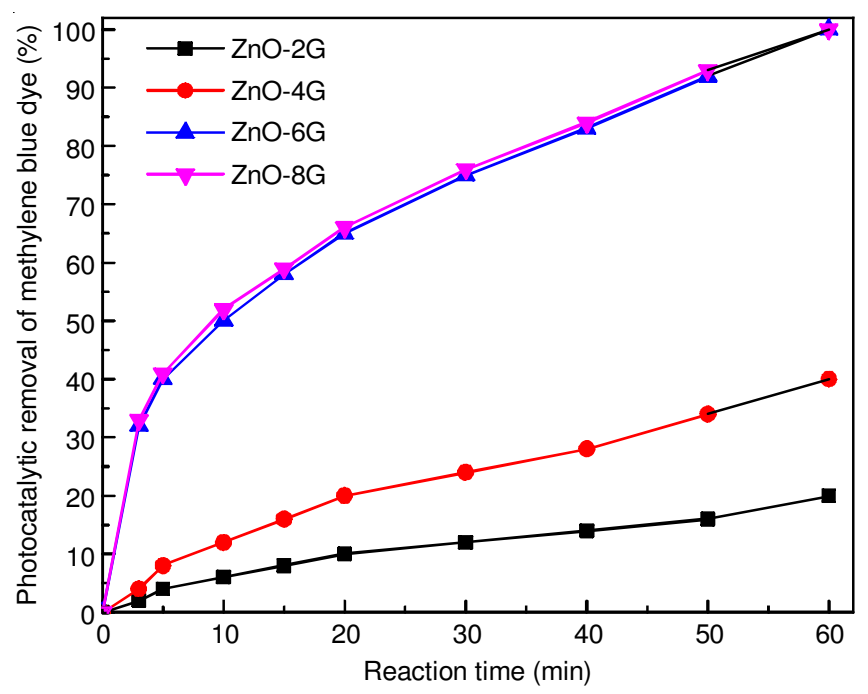

Fig. 4. Effect of different concentration of glycine on photocatalytic activity of $\mathrm{ZnO}$ nanoparticles for degradation of methylene blue

significant effect on the photocatalytic activity of $\mathrm{ZnO}$. Therefore, concentration of glycine is acting an essential role in the control band gap and the photocatalytic activity of the $\mathrm{ZnO}$ photocatalyst. ZnO-6G photocatalyst has the highest photocatalytic activity.

Effect of dose of $\mathrm{ZnO}-6 \mathrm{G}$ on degradation of methylene blue is shown in Fig. 5. The marks expose that the photocatalytic activity of $\mathrm{ZnO}-6 \mathrm{G}$ photocatalyst increased from 61 to $100 \%$ by increasing the dose of $\mathrm{ZnO}-6 \mathrm{G}$ photocatalyst from 0.4 to 0.8 $\mathrm{g} / \mathrm{L}$, respectively. Increasing the dose of $\mathrm{ZnO}-6 \mathrm{G}$ photocatalyst from 0.8 to $1.2 \mathrm{~g} / \mathrm{L}$ decreases the reaction time required for the complete degradation of methylene blue from 60 to $40 \mathrm{~min}$, respectively. Due to rising dose of $\mathrm{ZnO}-6 \mathrm{G}$ photocatalyst increases the number of active sites available for photocatalytic oxidation of methylene blue. However, increasing the dose of $\mathrm{ZnO}-6 \mathrm{G}$ above $1.2 \mathrm{~g} / \mathrm{L}$ increases the reaction time again from 40 to $60 \mathrm{~min}$ and decrease photocatalytic activity from 100 to $94 \%$. Increasing the dose above a certain amount hinders the penetration of light to the surface of the photocatalyst and thus either decreases photocatalytic activity or increases reaction time. 


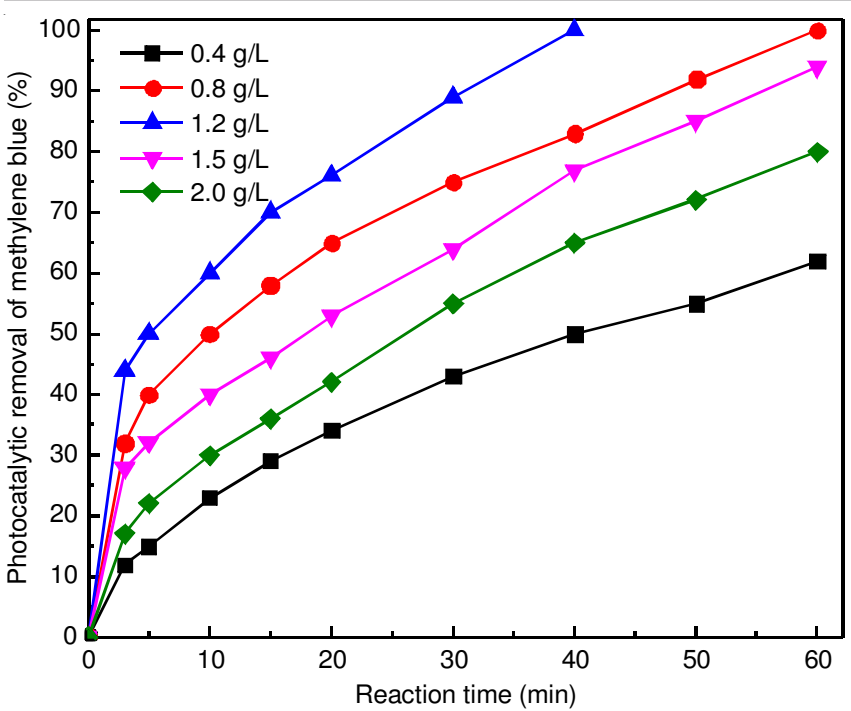

Fig. 5. Effect of dose of $\mathrm{ZnO}-6 \mathrm{G}$ on degradation of methylene blue

Recycling and reuse of $\mathrm{ZnO}-6 \mathrm{G}$ photocatalyst for degradation of methylene blue is shown in Fig. 6. The results reveal that $\mathrm{ZnO}-6 \mathrm{G}$ photocatalyst has photocatalytic stability for the degradation of methylene blue for five times.

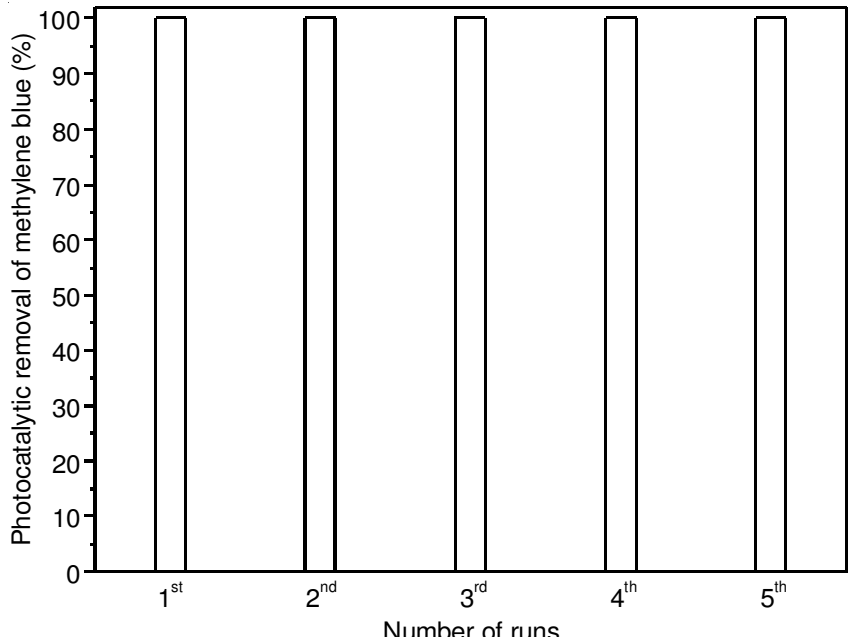

Fig. 6. Recycling and reuse of $\mathrm{ZnO}-6 \mathrm{G}$ photocatalyst for degradation of methylene blue

\section{Conclusion}

Hydrothermal method in presence of glycine as surfactant was used to prepare $\mathrm{ZnO}$ nanoparticles. Different techniques were used to characterize the prepared materials. The results demonstrated that the photocatalytic activity and band gap of $\mathrm{ZnO}$ nanoparticles can be controlled by controlling the concentration of glycine. The photocatalytic activity of $\mathrm{ZnO}-6 \mathrm{G}$ sample nanoparticle for the degradation of methylene blue is highest. ZnO-6G photocatalyst has photocatalytic stability for the degradation of methylene blue for five times. The band gap, particle size, BET surface area of zinc oxide can be controlled by control concentration of glycine.

\section{REFERENCES}

1. A. Fujishima and K. Honda, Nature, 238, 37 (1972); https://doi.org/10.1038/238037a0.
2. A.O. Ibhadon and P. Fitzpatrick, Catalysts, 3, 189 (2013); https://doi.org/10.3390/catal3010189.

3. M.M. Mahlambi, C.J. Ngila and B.B. Mamba, J. Nanomater, 2015, 5 (2015); https://doi.org/10.1155/2015/790173.

4. K. Mondal and A. Sharma, RSC Adv., 6, 83589 (2016); https://doi.org/10.1039/C6RA18102C.

5. R. Ahmad, Z. Ahmad, A.U. Khan, N.R. Mastoi, M. Aslam and J. Kim, J. Environ. Chem. Eng., 4, 4143 (2016); https://doi.org/10.1016/j.jece.2016.09.009.

6. M.R. Hoffmann, S.T. Martin, W. Choi and D.W. Bahnemann, Chem. Rev., 95, 69 (1995);

https://doi.org/10.1021/cr00033a004.

7. K. Nakata and A. Fujishima, J. Photochem. Photobiol. Photochem. Rev., 13, 169 (2012); https://doi.org/10.1016/j.jphotochemrev.2012.06.001.

8. L.K. Pan, X.J. Liu, Z. Sun and C.Q. Sun, J. Mater. Chem. A Mater. Energy Sustain., 1, 8299 (2013); https://doi.org/10.1039/c3ta10981j.

9. X. Xu, C. Randorn, P. Efstathiou and J.T. Irvine, Nat. Mater., 11, 595 (2012); https://doi.org/10.1038/nmat3312.

10. D. Ravelli, D. Dondi, M. Fagnoni and A. Albini, Chem. Soc. Rev., 38, 1999 (2009);

https://doi.org/10.1039/b714786b

11. T.P. Chou, Q.F. Zhang, G.E. Fryxell and G.Z. Cao, Adv. Mater., 19, 2588 (2007); https://doi.org/10.1002/adma.200602927.

12. K. Park, Q. Zhang, B.B. Garcia, X. Zhou, Y.-H. Jeong and G. Cao, Adv. Mater., 22, 2329 (2010); https://doi.org/10.1002/adma.200903219.

13. S.B. Park and Y.C. Kang, J. Aerosol Sci., 28, 473 (1997); https://doi.org/10.1016/S0021-8502(97)85236-6.

14. S. Anandan, A. Vinu, T. Mori, N. Gokulakrishnan, P. Srinivasu, V. Murugesan and K. Ariga, Catal. Commun., 8, 1377 (2007); https://doi.org/10.1016/j.catcom.2006.12.001.

15. J.J. Wu and C.H. Tseng, Appl. Catal. B, 66, 51 (2006); https://doi.org/10.1016/j.apcatb.2006.02.013.

16. Z.Q. Xu, H. Deng, J. Xie, Y. Li and X.T. Zu, Appl. Surf. Sci., 253, 476 (2007); https://doi.org/10.1016/j.apsusc.2005.12.113.

17. M. Yu, H. Qiu, X. Chen, H. Li and W. Gong, Mater. Chem. Phys., 126, 797 (2011) https://doi.org/10.1016/j.matchemphys.2010.12.041.

18. Y. Yang, Y. Li, L. Zhu, H. He, L. Hu, J. Huang, F. Hu, B. He and Z. Ye, Nanoscale, 5, 10461 (2013); https://doi.org/10.1039/c3nr03160h.

19. Y.-H. Lu, W.-H. Lin, C.-Y. Yang, Y.-H. Chiu, Y.-C. Pu, M.-H. Lee, Y.-C. Tseng and Y.-J.Hsu, Nanoscale, 6, 8796 (2014); https://doi.org/10.1039/C4NR01607F.

20. R. Saleh and N.F. Djaja, Spectrochim. Acta A Mol. Biomol. Spectrosc., 130, 581 (2014); https://doi.org/10.1016/j.saa.2014.03.089.

21. J. Kaur and S. Singhal, Ceram. Int., 40, 7417 (2014); https://doi.org/10.1016/i.ceramint.2013.12.088.

22. S. Kuriakose, B. Satpati and S. Mohapatra, Phys. Chem. Chem. Phys., 17, 25172 (2015); https://doi.org/10.1039/C5CP01681A

23. S.G. Kumar and K.S.R.K. Rao, RSC Adv., 5, 3306 (2015); https://doi.org/10.1039/C4RA13299H.

24. L.P. Zhu, W.Y. Huang, L.L. Ma, S.Y. Fu, Y. Yu and Z.J. Jia, Acta PhysicoChim. Sinica, 22, 1175 (2006).

25. S. Iijima, Nature, 354, 56 (1991); https://doi.org/10.1038/354056a0

26. T.A. Saleh, M.A. Gondal, Q.A. Drmosh, Z.H. Yamani and A. Al-Yamani, Chem. Eng. J., 166, 407 (2011); https://doi.org/10.1016/j.cej.2010.10.070.

27. X.J. Wang, S.W. Yao and X. Li, Chin. J. Chem., 27, 1317 (2009); https://doi.org/10.1002/cjoc.200990220.

28. L.P. Zhu, G.H. Liao, W.Y. Huang, L.L. Ma, Y. Yang, Y. Yu and S.Y. Fu, Mater. Sci. Eng. B, 163, 194 (2009); https://doi.org/10.1016/j.mseb.2009.05.021.

29. R.M. Mohamed and M.A. Salam, Mater. Res. Bull., 50, 85 (2014); https://doi.org/10.1016/j.materresbull.2013.10.031. 
30. K. Dai, G. Dawson, S. Yang, Z. Chen and L. Lu, Chem. Eng. J., 191, 571 (2012); https://doi.org/10.1016/j.cej.2012.03.008

31. H. Kataura, Y. Kumazawa, Y. Maniwa, I. Umezu, S. Suzuki, Y. Ohtsuka and Y. Achiba, Synth. Met., 103, 2555 (1999); https://doi.org/10.1016/S0379-6779(98)00278-1.

32. M.S. Dresselhaus, G. Dresselhaus and R. Saito, Carbon, 33, 883 (1995); https://doi.org/10.1016/0008-6223(95)00017-8.

33. P.C. Eklund, J.M. Holden and R.A. Jishi, Carbon, 33, 959 (1995); https://doi.org/10.1016/0008-6223(95)00035-C.

34. C. Fantini, A. Jorio, M. Souza, M.S. Strano, M.S. Dresselhaus and M.A. Pimenta, Phys. Rev. Lett., 93, 147406 (2004); https://doi.org/10.1103/PhysRevLett.93.147406.
35. S.J. Tans, M.H. Devore, H.J. Dai, A. Thess, R.E. Smalley, L.J. Geerligs and C. Dekker, Nature, 386, 474 (1997); https://doi.org/10.1038/386474a0.

36. M. Bockrath, D.H. Cobden, P.L. McEuen, N.G. Chopra, A. Zettl, A. Thess and R.E. Smalley, Science, 275, 1922 (1997); https://doi.org/10.1126/science.275.5308.1922.

37. Y. Cong, X. Li, Y. Qin, Z. Dong, G. Yuan, Z. Cui and X. Lai, Appl. Catal. $B, 107,128$ (2011);

https://doi.org/10.1016/j.apcatb.2011.07.005.

38. K. Woan, G. Pyrgiotakis and W. Sigmund, Adv. Mater, 21, 2233 (2009); https://doi.org/10.1002/adma.200802738.

39. W. Chen, X. Pan, M.G. Willinger, D.S. Su and X. Bao, J. Am. Chem. Soc., 128, 3136 (2006); https://doi.org/10.1021/ja0567211. 